\title{
Outcomes and effectiveness of bilateral percutaneous transluminal renal artery stenting in patients with critical bilateral renal artery stenosis
}

\author{
Mustafa Yildiz ${ }^{1}$, Suleyman Karakoyun ${ }^{1}$, Banu Sahin Yildiz ${ }^{2}$, \\ Alparslan Sahin ${ }^{3}$, Ibrahim Akin ${ }^{4}$ \\ ${ }^{1}$ Department of Cardiology, Kartal Kosuyolu Yüksek Ihtisas Educational and Research Hospital, Istanbul, Turkey \\ ${ }^{2}$ Deparment of Internal Medicine, Dr Lütfi Kirdar Educational and Research Hospital, Istanbul, Turkey \\ ${ }^{3}$ Department of Cardiology, Dr Sadi Konuk Educational and Research Hospital, Istanbul, Turkey \\ ${ }^{4}$ Department of Cardiology, Rostock University Medical Faculty, Rostock, Germany
}

\begin{abstract}
Background: The aim of this study was to assess the effects of percutaneous bilateral renal artery stenting in patients with atherosclerotic renal artery stenosis and in-hospital and 4 month outcome of the procedure, focusing on the changes in renal function and blood pressure. Methods: Five consecutive patients (mean age: $64.8 \pm 9.7$ years, 1 women) with bilateral renal artery stenoses underwent percutaneous interventions. We compared blood pressure, number of oral antihypertensive medications, and renal function changes preprocedure and postprocedure at 4 months follow-up.

Results: A total of 5 bilateral atherosclerotic renal artery stenosis patients underwent percutaneous transluminal renal angioplasty and 10 stents were placed. Although systolic and diastolic blood pressures were significantly decreased in follow-up period, glomerular filtration rates were not significantly changed as compared with baseline data $(p=0.009, p=0.008$, $p=1.00$, respectively). Also, the number of oral antihypertensive medications were significantly decreased at follow-up period $(p=0.03)$.

Conclusions: Bilateral renal artery stenting provides a beneficial outcome such as stabilization of renal functions, significant improvement in blood pressure control and reduction in the number of oral antihypertensive medications at follow-up. (Cardiol J 2013; 20, 1: 25-28)
\end{abstract}

Key words: bilateral renal artery stenosis, percutaneous renal intervention, renovascular hypertension

\section{Introduction}

Percutaneous transluminal renal interventions including angioplasty and stenting are important methods for treatment of atherosclerotic renal ar- tery stenoses [1]. However, as the procedure became broadly applied from the beginning conflicting results emerged. Although some patients showed major benefit after percutaneous renal interventions, others experienced further deteriora-

Address for correspondence: Dr. Mustafa Yildiz, MD, PhD, Prof. Cardiologist, Internal Medicine Specialist and Physiologist, Bayar Cad Gülbahar Sok Emniyet Sitesi D6, Kozyatagi, Istanbul, Turkey, tel: +90 021645978 00, telefax: +90 02164596321 , e-mail: mustafayilldiz@yahoo.com

Received: 15.09.2012 Accepted: 11.10.2012 
tion of renal function [2]. Today it is acknowledged that atherosclerotic renal artery stenoses is a complex clinical condition that ranges from asymptomatic disease to high grade bilateral disease complicated by progressive renal failure, recurrent pulmonary edema, and severe hypertension. Current indications for renal interventions have been partly guided by the Angioplasty and STenting for Renal Artery Lesions (ASTRAL) study [3] that has shown this therapy makes little impact upon major outcomes. Also, Chrysochou et al. [4] showed that subgroups including acute flash pulmonary edema and acute kidney injury might benefit from intervention. But, this conditions are a non-evidenced-based indication (Class I, Level of Evidence B) according to the American College of Cardiology/American Heart Association guidelines [5]. The aim of this study was to assess the effects of percutaneous bilateral renal artery stenting in patients with atherosclerotic renal artery stenosis and in-hospital and 4 month outcome of the procedure, focusing on the changes in renal function and blood pressure.

\section{Methods}

\section{Patients}

Five consecutive patients (mean age: $64.8 \pm$ \pm 9.7 years, 1 women) with bilateral renal artery stenoses underwent percutaneous interventions. Three patients was admitted with chest pain and drug resistant hypertension [6]. Also, 2 patients was admitted hypertension and pulmonary edema. All patients were diagnosed with luminal narrowing $\geq 70 \%$ by renal Doppler ultrasonography or computed tomography before intervention. All subjects gave their consent for inclusion in the study. The investigation conforms with the principles outlined in the Decleration of Helsinki. All the patients was treated at the time of examination with minimum 3 antihypertensive drugs such as angiotensin receptor blockers, angiotensin-converting-enzyme inhibitors, nitrates, diuretics, alpha-blockers, beta-blockers and calcium channel blockers. The blood pressure was measured, using a mercury sphygmomanometer with a cuff appropriate to the arm circumference (Korotkoff phase I for systolic blood pressure and $\mathrm{V}$ for diastolic blood pressure). Blood pressure measurements were performed twice for each subject and their mean was used for statistical analysis. Estimated glomerular filtration rate was calculated using the Cockcroft-Gault formula [7]. The patients were followed for 4 months. Baseline patient demographics and procedural data was presented in Table 1.
Table 1. Baseline patient demographics and procedural data.

\begin{tabular}{|c|c|}
\hline Parameters & Patients \\
\hline $\operatorname{Sex}(M / F)$ & $4 / 1$ \\
\hline Age (years) & $64.8 \pm 9.7$ \\
\hline Diabetes & $1(\mathrm{~F})$ \\
\hline Hypertension & 5 \\
\hline Hyperlipidemia & $1(\mathrm{M})$ \\
\hline Coronary artery disease & $3(1 \mathrm{~F})$ \\
\hline $\begin{array}{l}\text { Prior coronary bypass surgery } \\
\text { and/or } \mathrm{PCl}\end{array}$ & $2(1 \mathrm{~F}) \mathrm{PCl}$ \\
\hline Previous smoker & $1(\mathrm{M})$ \\
\hline Number of drugs-prestenting & $3.40 \pm 0.54$ \\
\hline Number of drugs-poststenting & $1.40 \pm 0.54$ \\
\hline Normal sinus rhythm & 5 \\
\hline Ejection fraction (\%) & $62.40 \pm 3.71$ \\
\hline LVH and diastolic dysfunction & 5 \\
\hline \multicolumn{2}{|l|}{ Systolic blood pressure [mm Hg]: } \\
\hline Preprocedural & $178.00 \pm 16.43$ \\
\hline Postprocedural & $142.00 \pm 16.41$ \\
\hline 4 months & $132.00 \pm 8.36$ \\
\hline \multicolumn{2}{|l|}{ Distolic blood pressure [mm Hg]: } \\
\hline Preprocedural & $97.00 \pm 8.35$ \\
\hline Postprocedural & $84.00 \pm 5.47$ \\
\hline 4 months & $76.00 \pm 5.45$ \\
\hline \multicolumn{2}{|l|}{ Glomerular filtration rate $[\mathrm{ml} / \mathrm{min}]$ : } \\
\hline Preprocedural & $30.38 \pm 7.63$ \\
\hline Postprocedural & $30.27 \pm 8.47$ \\
\hline 4 months & $29.96 \pm 7.16$ \\
\hline Leukocytes [/ $\mu \mathrm{L}]$ & $7.56 \pm 2.09$ \\
\hline Hemoglobin $[\mathrm{g} / \mathrm{dL}]$ & $11.34 \pm 0.39$ \\
\hline Platelets $[/ \mu \mathrm{L}]$ & $322.00 \pm 91.23$ \\
\hline Sodium [mEq/L] & $139.80 \pm 2.38$ \\
\hline Potassium [mEq/L] & $4.38 \pm 0.68$ \\
\hline Choloride $[\mathrm{mmol} / \mathrm{L}]$ & $106.00 \pm 3.16$ \\
\hline Albumin $[\mathrm{mg} / \mathrm{dL}]$ & $3.96 \pm 0.43$ \\
\hline Sedimentation $[\mathrm{mm} / \mathrm{h}]$ & $22.00 \pm 5.19$ \\
\hline Brain natriuretic peptide $[\mathrm{pg} / \mathrm{mL}]$ & $341.00 \pm 304.05$ \\
\hline Glucose $[\mathrm{mg} / \mathrm{dL}]$ & $103.00 \pm 10.83$ \\
\hline Low-density lipoprotein [mg/dL] & $114.20 \pm 31.15$ \\
\hline High-density lipoprotein [mg/dL] & $34.18 \pm 10.29$ \\
\hline Cholesterol $[\mathrm{mg} / \mathrm{dL}]$ & $200.20 \pm 43.92$ \\
\hline Trygliceride [mg/dL] & $193.80 \pm 27.45$ \\
\hline $\begin{array}{l}\text { Right renal artery } \\
\text { stent size }[\mathrm{cm}]\end{array}$ & $\begin{array}{r}(14.0 \pm 1.22) \\
\times(6.20 \pm 0.83)\end{array}$ \\
\hline $\begin{array}{l}\text { Left renal artery } \\
\text { stent size }[\mathrm{cm}]\end{array}$ & $\begin{array}{r}(15.02 \pm 2.12) \\
\times(6.40 \pm 0.54)\end{array}$ \\
\hline $\begin{array}{l}\text { Postdilatation baloon } \\
\text { pressure [atm] }\end{array}$ & $8.80 \pm 1.30$ \\
\hline
\end{tabular}




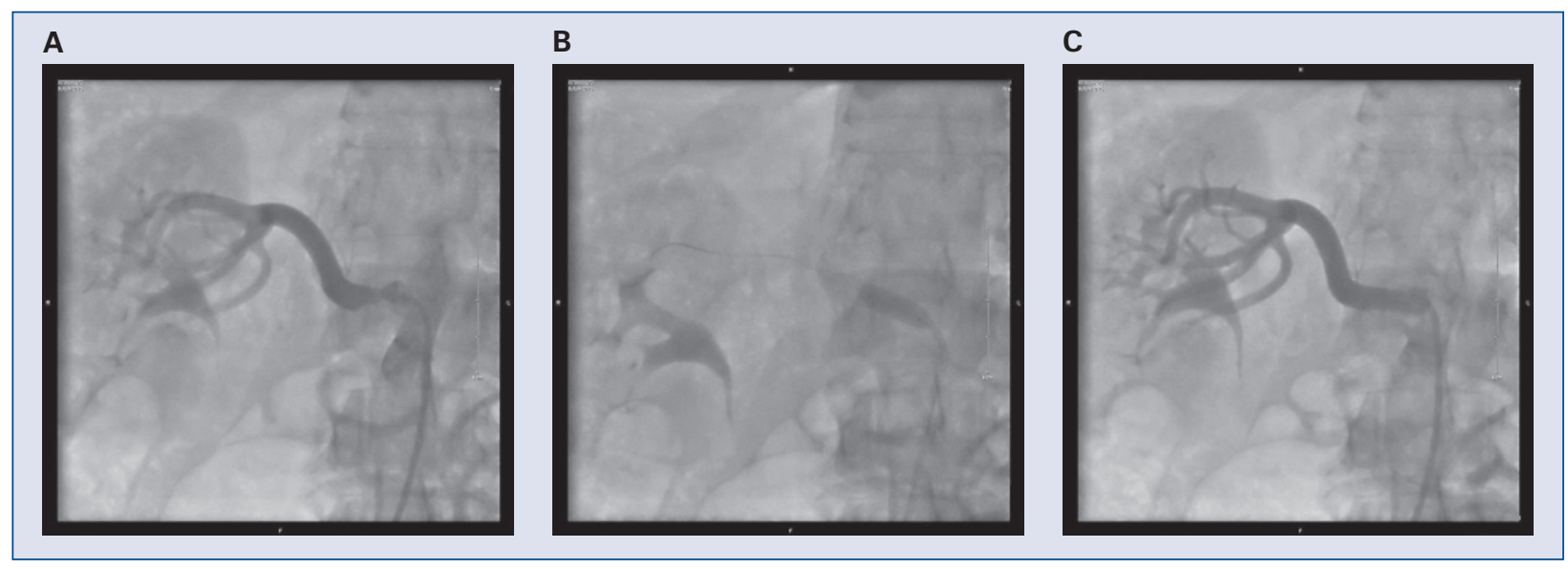

Figure 1A-C. The guide wire was passed through the stenosis and a balloon-expandable stent was placed via the guide wire.

\section{Percutaneous technique}

Femoral arterial puncture was performed in all patients, and all procedures were performed through a $6-8 \mathrm{~F}$ sheath introducer, with a renal artery guiding catheter introduced via a $0.36-\mathrm{mm}$ or $0.46-\mathrm{mm}$ guide wire. The guide wire was passed through the stenosis and a balloon-expandable stent was placed via the guide wire (Fig. 1A-C). For treatment of ostial stenoses, the stent was positioned so that 1 to $2 \mathrm{~mm}$ protruded into the aortic lumen, ensuring complete coverage of the aortic plaque. An intervention was considered technically successful if the residual stenosis was $<30 \%$. Antiplatelet therapy was started at least 1 day before intervention and routinely consisted of $75 \mathrm{mg}$ of clopidogrel daily for 3 months and $100 \mathrm{mg}$ of aspirin indefinitely. Immediately before the intervention, we administered a bolus dose of $5000 \mathrm{IU}$ of heparin.

\section{Statistical analysis}

Statistics were obtained using the ready-to-use programme of SPSS version 8.0. All the values were expressed as mean \pm standard deviation. The obtained results for systolic blood pressure, diastolic blood pressure and glomerular filtration rates were assessed by non-parametrik Friedman test. Number of drugs use for hypertension was assessed by non-parametrik Wilcoxon signed ranks test. The significance level was set at a value of $\mathrm{p}<0.05$.

\section{Results}

A total of 5 bilateral atherosclerotic renal artery stenosis patients underwent percutaneous transluminal renal angioplasty and 10 stents were placed (Table 1). There were not any complication during interventional procedure. The findings of preprocedural, postprocedural and 4 months later were presented in Table 1. Although systolic and diastolic blood pressures were significantly decreased at follow-up period, glomerular filtration rates were not significantly changed as compared with baseline data $(\mathrm{p}=0.009, \mathrm{p}=0.008, \mathrm{p}=1.00$, respectively). Also, the number of oral antihypertensive medications were significantly decreased at follow-up period $(\mathrm{p}=0.03)$.

\section{Discussion}

Atherosclerotic renal artery stenosis may be associated with renovascular hypertension, increased cardiovascular morbidity and mortality [2]. Patients with bilateral critical atherosclerotic renal artery stenosis are at increased risk for hypertension and acute pulmonary edema [4]. Resistant hypertension, is defined as blood pressure that remains above goal in spite of the concurrent use of three antihypertensive agents of different classes [6], and acute pulmonary edema are accepted as 1 of the few indications for consideration of renal artery revascularization $[4,8,9]$. However, this is Class I, Level of Evidence B indications according to the American College of Cardiology/American Heart Association guidelines [5]. Atherosclerotic renal artery stenosis are usually located in the renal artery ostium, and many are extensions of calcified aortic plaque. Although, these tight and calcified lesions tend to rebound to their original shape with balloon angioplasty alone [10], we used balloon expandable stent that provides the additional 
force needed to permanently disrupt the lesions, leading to a longer-lasting result [10]. This study showed that percutaneous transluminal bilateral renal artery stenting significantly reduced both systolic and diastolic blood pressure at postprocedural period compared to baseline. Also, it demonstrated a significant improvement in blood pressure control and reduction in the number of oral antihypertensive medications at follow-up period, as in other studies $[4,10]$.

Although serum creatinine levels may be altered by some factors such as body muscle mass and age, we used glomerular filtration rate using the Cockcroft-Gault formula [7], which is a more sensitive marker of renal function. Revascularization of the renal artery with stenting to preserve renal function is based on the assumption that ischemia contributes to renal insufficiency and that correction of the stenosis and restoration of renal perfusion will stabilize, as in our study, or improve renal function [10]. Considering the dialysis patients who reduces life expectancy and quality of life, any stabilization of renal function should be regarded as a beneficial outcome.

\section{Limitations of the study}

These conclusions may not extand to the great population, therefore; the results of this study will need confirmation in larger studies.

\section{Conclusions}

In conclusion, the findings of our study indicate that bilateral renal artery stenting provides a beneficial outcome such as stabilization of renal functions, significant improvement in blood pressure control and reduction in the number of oral antihypertensive medications at follow-up.

Conflict of interest: none declared

\section{References}

1. van de Ven PJ, Kaatee R, Beutler JJ et al. Arterial stenting and balloon angioplasty in ostial atherosclerotic renovascular disease: A randomised trial. Lancet, 1999; 353: 282-286.

2. Textor SC, Wilcox CS. Renal artery stenosis: A common, treatable cause of renal failure? Annu Rev Med, 2001; 52: 421-442.

3. Wheatley K, Ives N, Gray R et al. ASTRAL Investigators. Revascularization versus medical therapy for renal-artery stenosis. N Engl J Med, 2009; 361: 1953-1962.

4. Chrysochou C, Schmitt M, Siddals K, Hudson J, Fitchet A, Kalra PA. Reverse cardiac remodelling and renal functional improvement following bilateral renal arterystenting for flash pulmonary oedema. Nephrol Dial Transplant, 2012 [Epub ahead of print].

5. Hirsch AT, Haskal ZJ, Hertzer NR et al. ACC/AHA Guidelines for the management of patients with peripheral arterial disease (lower extremity, renal, mesenteric, and abdominal aortic): A collaborative report from the American Associations for Vascular Surgery/Society for Vascular Surgery, Society for Cardiovascular Angiography and Interventions, Society for Vascular Medicine and Biology, Society of Interventional Radiology, and the ACC/AHA Task Force on Practice Guidelines (writing committee to develop guidelines for the management of patients with peripheral arterial disease)-summary of recommendations. J Vasc Interv Radiol, 2006; 17: 1383-1397.

6. Calhoun DA, Jones D, Textor S et al. Resistant hypertension: diagnosis, evaluation, and treatment. A scientific statement from the American Heart Association Professional Education Committee of the Council for High Blood Pressure Research. Hypertension, 2008; 51: 1403-1419.

7. Cockcroft DW, Gault MH. Prediction of creatinine clearance from serum creatinine. Nephron, 1976; 16: 31-41.

8. Rimoldi SF, Yuzefpolskaya M, Allemann Y, Messerli F. Flash pulmonary edema. Prog Cardiovasc Dis, 2009; 52: 249-259.

9. Bloch MJ, Trost DW, Pickering TG, Sos TA, August P. Prevention of recurrent pulmonary edema in patients with bilateral renovascular disease through renal artery stent placement. Am J Hypertens, 1999; 12 (1 Part 1): 1-7.

10. Liao CJ, Yang BZ, Wang ZG. Percutaneous transluminal renal angioplasty with stent is effective for blood pressure control andrenal function improvement in atherosclerotic renal artery stenosis patients. Chin Med J (Engl), 2012; 125: 1363-1368 . 